\title{
DILEMA IDENTITAS KULIT HITAM MELALUI PERNIKAHAN ANTAR-RAS DALAM DREAMS FROM MY FATHER KARYA BARRACK OBAMA
}

\author{
Qori Islami Aris \\ Fakultas Ilmu Budaya, Universitas Lancang Kuning, Pekanbaru - Riau \\ Email: qoriislamibintiaris@unilak.ac.id
}

Naskah diterima: 26 November; direvisi: 4 Desember; disetujui: 14 Desember

\begin{abstract}
Abstrak
Laki-laki dan perempuan biracial di AS, khususnya mereka yang memiliki warisan hitamputih, terus-menerus dihadapkan pada krisis identitas pribadi, di mana mereka tidak dapat menyejajarkan diri dengan kedua sisi ras atau etnis mereka. Barack Obama, presiden petahana AS, juga mengalami situasi yang membingungkan selama tahap pengembangan kedirian dan identitasnya. Penelitian ini menyajikan penjelasan yang berkaitan dengan tantangan yang dihadapi Obama dalam pencarian identitasnya. Penelitian ini juga menyelidiki sejauh mana supremasi kulit putih dan inferioritas kulit hitam yang didesain sedemikian rupa masih terus berlanjut hingga saat ini. Dari penjabaran dapat disimpulkan bahwa ini merupakan kelemahan AS dalam upaya untuk mencapai keadilan dan kesetaraan antara Kulit Putih dan Hitam, bukanlah sarana yang dibutuhkan, melainkan realisasi dan penerimaan tentang pentingnya multirasalitas. Peneliti menggunakan metode kualitatif sebagai metode penelitian dalam upaya untuk memperoleh pemahaman secara mendalam tentang realitas sosial yang digambarkan dalam memoar.
\end{abstract}

Kata kunci: Kajian Budaya, Teori Critical Race, Nasionalisme Kulit Hitam, Rasisme Buta Warna

\begin{abstract}
Biracial men and women in the U.S., particularly those with a black and white heritage are constantly faced with personal identity crisis, in which they are unable to align themselves with either side of their race or ethnicity. Barack Obama, the incumbent president of the U.S., also experienced such puzzling situations during the stages of his selfhood and identity development. This research presents an explanation relating to the challenges Obama faced in his search for identity. It also investigates the extent to which white supremacy and black inferiority by design still persists until today. It concludes by stating that what the U.S. is lacking in its effort to achieve justice and equality between the Caucasians and the Negroes, is not the means, but the realization and acceptance on the importance of multiraciality. The researcher employed qualitative method as the mode of research in an attempt to gain an in-depth understanding of the social realities depicted in the memoir.
\end{abstract}

Keywords: Cultural Studies, Critical Race Theory, Black Nationalism, Colorblind Racism 


\section{Pendahuluan}

Manusia terus-menerus menghadapi dilema dalam hidup mereka. Ketika seseorang melihat seseorang yang tampaknya miskin tetapi ia cukup berbadan sehat tengah duduk di tengah jalan padat untuk meminta sedekah, di satu sisi kita dihadapkan dengan konflik batin untuk memberikan bantuan dengan menekankan kebaikan dengan harapan agar orang berbadan sehat tersebut menjadi lebih mandiri. Seorang wanita Bali yang tinggal di era Islamilisasi, memakai pakaian tanpa penutup dada yang sejak zaman dahulu adalah bagian dari warisan budaya nya, goyah dalam keputusannya untuk meninggalkan tradisi etnis dan merangkul Islam sebagai bentuk kesopanan perempuan. Dari kepentingan tertentu, kasus kedua dapat menimbulkan dilema ketat karena menyangkut identitas budaya: konsepsi seseorang tentang individualitas dan afiliasi kelompoknya.

Sebagai identifier utama identitas pribadi, identitas budaya terkait erat dengan etnis, ras, agama, jenis kelamin, keturunan, bahasa, dan kebangsaan. Sebuah pertanyaan dari etnis dan ras, khususnya, mungkin menjadi proses yang sederhana yang tidak meninggalkan ketidakjelasan, atau yang membingungkan. Namun hal ini berbeda bagi seseorang yang berdiri di garis kebingungan yang berkaitan dengan identitas etno-rasial dengan berlatar belakang multiras nya. Kompleksitas masalah mungkin lebih diperburuk oleh kesalahpahaman masyarakat dari etnis dan ras, yang sering dirusak oleh motivasi politik dan kebijakan. Bangsa Arab, misalnya, secara stereotip dianggap kelompok etnis barbar oleh Oksidental, keberadaan Islam sebagai agama mayoritas Bangsa Arab di Barat menghadapi tekanan Barat berupa propaganda media, sentimen, dan teror, karena penggambaran media Barat yang berlebihan dari perselisihan tidak harmonis yang terjadi di beberapa negara Tengah-Barat. Tipifikasi ini menyebabkan seseorang dari ras tertentu atau etnis tertentu, yang tinggal di negara di mana bagian dari identitas etno-rasialnya dipandang rendah, jijik dan hina, merasa hancur dari masyarakat.

Di Amerika Serikat, orang yang lahir dari antar ras atau perkawinan antar-ras, sering menemukan diri mereka tertusuk oleh tanduk dilema identitas etno-rasial. Mereka menghadapi isu-isu kategorisasi rasial dan pandangan publik tentang identitas multiras mereka. Di masa lalu, sebelum diberlakukannya Loving v. Virginia, 388 US 1 (1967), yang diselenggarakan undangundang anti-antar ras inkonstitusional, pernikahan antar-ras dianggap sebagai tindakan memfitnah, terutama salah satu antara Orang Kulit Putih (Kaukasia) dan Negro. Davis Knight, cicit dari seorang tentara gerilya terkenal, Newton Knight yang berbalik melawan Konfederasi selama Perang Saudara Amerika, dijatuhi hukuman penjara lima tahun pada tahun 1948 meskipun dia hanya memiliki keturunan Afrika ke-delapan. Di era modernisasi ini, parodi peradilan tersebut tidak akan dibiarkan terjadi. Hal ini terbukti oleh fakta bahwa selama sejarah AS, telah ada hanya satu presiden kulit hitam, Barack Hussein Obama (meskipun mengkategorikan dirinya sebagai 'Kulit Hitam' adalah kekeliruan, karena ia adalah biracial); atau insiden terbaru di mana polisi Cleveland menembak dan membunuh seorang anak laki-laki kulit hitam berumur dua belas tahun, Tamir Rice, setelah salah mengira bahwa senjata replika yang dimainkan anak itu adalah pistol sungguhan. Dengan demikian, tidak mengherankan untuk menemukan orang multiras yang merasa bingung dan terganggu oleh afiliasi rasnya.

Ada sebuah banyak kasus antar-ras di seluruh dunia yang menimbulkan identitas dilemma. Hal ini menyebabkan penulis tertarik untuk menggali lebih jauh sebuah karya sastra ke dalam dilema identitas etno-rasial, dan salah satunya adalah memoar oleh Barack Obama, Dreams from My Father (A Story of Race and Inheritance). Memoar itu sendiri adalah sebuah meditasi pada kisah hidup Barack Hussein Obama yang beresonansi dengan konsep sentral dari identitas seorang Amerika dengan latar belakang campuran: yang campuran dari ras dominan di AS, Kaukasia dan kelompok minoritas, perbudakan rasial di masa lalu, orang-orang Negro.

\section{Tinjauan Pustaka}

Teori Critical-Race, disingkat CRT (Critical

Race Theory) adalah disiplin akademis yang kritis meneliti realitas masyarakat dan budaya, terutama yang berkaitan dengan ras dan etnis. UCLA School of Public Affairs mendefinisikan Teori Critical-Race sebagai berikut:

CRT recognizes that racism is engrained in the fabric and system of the American 
society. The individual racist need not exist to note that institutional racism is pervasive in the dominant culture. This is the analytical lens that CRT uses in examining existing power structures. CRT identifies that these power structures are based on white privilege and white supremacy, which perpetuates the marginalization of people of color. CRT also rejects the traditions of liberalism and meritocracy. Legal discourse says that the law is neutral and colorblind, however, CRT challenges this legal "truth" by examining liberalism and meritocracy as a vehicle for self-interest, power, and privilege. CRT also recognizes that liberalism and meritocracy are often stories heard from those with wealth, power, and privilege. These stories paint a false picture of meritocracy; everyone who works hard can attain wealth, power, and privilege while ignoring the systemic inequalities that institutional racism provides.

CRT mengakui bahwa rasisme adalah berurat berakar dalam sistem dari masyarakat Amerika. Rasis individu tidak perlu ada untuk dicatat bahwa rasisme kelembagaan meresap dalam budaya yang dominan. Ini adalah lensa analitis yang digunakan CRT dalam memeriksa struktur kekuatan yang ada. CRT mengidentifikasi bahwa struktur kekuasaan ini didasarkan pada hak istimewa kulit putih dan supremasi kulit putih, yang mengabadikan marginalisasi orang kulit berwarna. CRT juga menolak tradisi liberalisme dan meritokrasi. wacana hukum mengatakan bahwa hukum adalah netral dan buta warna, namun, CRT menantang ini hukum "kebenaran" dengan memeriksa liberalisme dan meritokrasi sebagai kendaraan untuk kepentingan pribadi, kekuasaan, dan hak istimewa. CRT juga mengakui bahwa liberalisme dan meritokrasi sering mendengar cerita dari orang-orang dengan kekayaan, kekuasaan, dan hak istimewa. Cerita-cerita ini melukiskan gambaran palsu meritokrasi; semua orang yang bekerja keras dapat mencapai kekayaan, kekuasaan, dan hak istimewa sementara mengabaikan ketidaksetaraan sistemik yang disediakan oleh rasisme institusional.

\subsection{Nasionalisme Kulit Hitam}

Nasionalisme kulit hitam adalah sebuah ideologi yang mendukung kesatuan kolektif orang kulit hitam untuk bergerak maju dalam perjuangan mereka sendiri untuk kebebasan, keadilan, dan kesetaraan. Hal ini dibangun di atas prinsip bahwa orang Negro harus memiliki harga diri, penerimaan diri, bermartabat, dan kebanggaan dalam warisan etno-rasial mereka sendiri; dan bahwa satu-satunya cara bagi orang kulit hitam untuk mencapai kemerdekaan sejati dan keadilan adalah melalui separatisme dari supremasi kulit putih inheren-rasis dengan memiliki kontrol penuh dari gerakan mereka sendiri, serta lembaga-lembaga politik, sosial, dan ekonomi dalam masyarakat mereka sendiri.

\subsection{Rasisme Buta Warna (Colorblind Rasism)}

Rasisme Buta Warna, juga dikenal sebagai Rasisme Permusuhan, adalah rasisme tanpa menjadi 'rasis'; semacam teka-teki terkait dengan masalah rasisme di mana hampir tidak ada satu pun, yang ingin melihat diri mereka sebagai rasis, namun, kebenaran adalah rasisme masih tetap berlangsung, nyata dan ulet. (Memmi di Bonilla-Silva, 2006: 1)

Hal ini sering dimanifestasikan dalam diri proklamasi yang satu ini tidak rasis, sementara pada kenyataannya, orang tersebut memiliki kesalahpahaman tersembunyi atau prasangka mengenai ras lainnya. Pernyataan seperti 'Whites never seem to do anything bad' and 'It is not that we are racists, but black people always blame their poverty on the inequality of the welfare system; the truth is they are a bunch of lazy people', ini adalah contoh rasisme buta warna.

\section{Metode Penulisan}

Dreams from My Father, Sebuah memoar yang ditulis oleh Barack Obama, pertama kali diterbitkan pada tahun 1995, tak lama sebelum Obama memenangkan pemilihan Illinois legislatif negara. Buku itu dicetak ulang pada tahun 2004, setelah kemenangan Obama melalui pemilihan presiden. Sejak itu telah diterjemahkan ke dalam lebih dari dua puluh bahasa yang berbeda dan terjual lebih dari dua juta kopi dalam hardcover dan paperback.

Memoar, yang terbagi menjadi tiga bagian utama, menceritakan meditasinya pada identitas pribadi sepanjang hidupnya hingga pendaftaran di sekolah Hukum Harvard. Bagian pertama menceritakan latar belakang yang unik sebagai anak dari seorang ayah Kenya dan ibu kulit putih dari Kansas dan masa kecilnya di Hawaii dan Indonesia. Bagian kedua membahas pengalamannya sebagai seorang siswa dan pekerjaannya sebagai organizer masyarakat di Chicago pada tahun 1980-an. Bagian akhir dari buku ini menjelaskan tentang perjalanannya ke 
tanah Afrika, ke tanah keluarga besarnya di Kenya dan rekonsiliasi dirinya sendiri atas warisan leluhurnya.

Isi buku ini berkisar pada konsep kedirian, identitas budaya, afiliasi ras, nasionalisme kulit hitam, dan rasisme buta warna, disajikan secara keseluruhan. Konsepkonsep ini sejalan dengan tujuan holistik dari penulisan ini dan dengan demikian, mendorong penulis untuk meneliti memoar sebagai objek penulisan.

\section{Hasil dan Pembahasan}

\subsection{Tantangan Obama sebagai seorang Amerika biracial}

Bahkan di era modernisasi ini, yang telah dijuluki sebagai zaman pasca-ras oleh Amerika, zaman di mana bebas dari segregasi rasial, hidup sebagai orang dengan latar belakang campuran di AS telah terbukti masih 'menantang'. Sering kali, individu biracial mungkin diminta untuk mengidentifikasi dirinya dengan salah satu akar, sebuah etnis yang mungkin sebagian besar sejalan dengan dirinya. Sebagai anak seorang ibu Kaukasia dan seorang ayah Afrika, Obama juga menghadapi tantangan serupa yang dialami oleh orang Amerika biracial lainnya selama bertahuntahun terhadap pembentukan kedirian dan identitasnya. Selama masa kanak-kanaknya, ia dibesarkan di bawah perawatan dan pengawasan 'kakek-nenek putihnya', dia tidak memiliki kesadaran diri mengenai identitasnya sendiri. Hal itu terus berlangsung hingga ia sampai ke Hawai setelah menghabiskan 4 tahun di Indonesia, ia mulai mengidentifikasi dirinya sebagai seorang remaja kulit hitam, namun tentu saja itu tidak datang tanpa perjuangan. Dalam memoarnya, Dreams from My Father, ia menguraikan pergolakan batin yang dirasakannya, rasa rendah diri dan inferioritas akibat akar biracialnya: "I kept finding the same anguish, the same doubt, a self-contempt that neither irony not intellect seemed able to deflect." Dia terus-menerus mengalami dilema karena harus mengidentifikasi dengan satu ras sementara membuang setengah lainnya.

Hal ini tidak biasa bagi seorang individu ras campuran di AS untuk merasa tersisih dari kelompok sebaya mereka karena ketidakpastian mereka tentang identitas mereka sendiri. Perasaan ini terbit dari keraguan, perasaan hina, dan rendah diri diperkuat ketika mereka terlibat dalam kelompok dan kegiatan berdasarkan ras atau etnis, di mana godaan (bully) berbasis ras dan intimidasi mungkin terjadi. Mereka mulai menghadapi tekanan teman sebaya yang
Qori Islami Aris

berkaitan dengan etnis warisan mereka, terpecah antara dua budaya mereka. Lebih buruk lagi, jika bagian dari identitas budaya seseorang dipandang dengan jijik dan hina, seperti dalam kasus Blasteran (setengah hitam) dan Quadroon (seperempat hitam), mereka mungkin menjadi sasaran prasangka negatif.

\subsection{Supremasi Kulit Putih dan Inferioritas Kulit Hitam}

Bahkan hingga saat ini, supremasi kulit putih masih ada di AS dengan keyakinan bahwa kulit putih lebih unggul dari kulit hitam, berakar dari latar belakang sejarah di negeri ini. Di masa lalu, pada saat di mana negara-negara Selatan AS masih sangat tergantung pada tanaman pertanian seperti pertanian dan perkebunan gula, beras, dan kapas, pemanfaatan lembaga perbudakan adalah sebuah kebutuhan dan keharusan, hebatnya lagi, disahkan. Ratusan ribu orang Negro diimpor melalui perdagangan budak lintas benua untuk mengurangi biaya tenaga kerja dan meningkatkan produktivitas. Dengan demikian, tidak mengherankan bahwa supremasi kulit putih melihat orang Negro sebagai makhluk inferior dalam hal intelek dan kemampuan, kemudian diupayakan untuk melembagakan Inferioritas Kulit Hitam.

Inferioritas Kulit Hitam adalah proses sadar, disengaja dan sistematis yang dimanfaatkan secara khusus oleh sistem sosial supremasi kulit putih, sebagaimana yang dilakukan oleh semua lembaga-lembaga besar dan untuk lingkup sempitnya adalah mencetak orang-orang tertentu dalam sistem itu. Dalam hal ini, orang-orang Negro, menjadi bawahan fungsional. Di bawah sistem supremasi kulit putih, semakin gelap kulit seseorang maka semakin besar 'inferioritas' tekanan yang dikenakan oleh sistem rasis. Kecemerlangan inferioritas adalah bahwa hal itu bisa membuat rasisme terang-terangan (Supremasi Kulit Putih) usang, sekaligus secara bersamaan menormalkan Supremasi Kulit Putih di Amerika. Menurut Bakari Kitwana, "Supremasi kulit putih tidak perlu khawatir tentang membuat orang kulit hitam tampak lebih rendah; mereka hanya perlu terus memberi mereka pendidikan rendah, perumahan, perawatan kesehatan, perawatan anak, dan sejenisnya, dan dalam satu atau dua generasi nanti."

Pada abad ke-21, masalah utama orang kulit hitam tidak lagi berupa garis warna yang samar-samar dipahami, melainkan "sikap inferioritas" yang juga dapat didefinisikan sebagai rasisme yang diinternalisasi. Rasisme 
yang diinternalisasi ditandai dengan penerimaan pesan negatif tentang kemampuan dan nilai intrinsik rasnya. Akibatnya, devaluasi diri terjadi, membuat korban merasa tidak layak dan tidak sebaik orang lain. Mereka mulai percaya bahwa orang kulit putih lebih unggul dan mereka lebih rendah.

\section{Kesimpulan}

Ada banyak kasus di mana seorang pria biracial, terutama yang memiliki campuran warisan putih dan hitam, merasa tertekan untuk memutuskan pihak mana dari keluarganya yang akan membaiat mereka. Ini menciptakan dilema identitas pribadi yang dapat merusak harga diri dan rasa berharga mereka. AS selalu diakui untuk menerima terhadap multirasialitas di atas kertas, bagaimanapun kenyataannya adalah, ada komitmen yang tidak memadai untuk pemberantasan rasisme di AS mengingat pembunuhan baru-baru ini dari seorang bocah hitam dua belas tahun, Tamir Rice oleh petugas kepolisian, lebih lanjut menegaskan bahwa prasangka rasial dan kesalahpahaman masih berlangsung di AS. Dengan demikian, negara harus belajar untuk menerima dan memahami keanekaragaman etno-budaya dengan lebih baik, dan tidak boleh mengesampingkan seseorang dengan latar belakang multirasial dalam satu kategori. Sebaliknya, itu harus memungkinkan individu dengan kesempatan yang layak untuk mengidentifikasi dengan campuran latar belakang dan merangkul semua akar mereka. Realisasi yang tajam tentang pentingnya ras dan multirasialitas di AS merupakan elemen penting yang akan membuka jalan menuju negara yang lebih baik, yang dibangun di atas keadilan dan kesetaraan di atas yang lain.

\section{Daftar Pustaka}

Bonilla, E. (2006). Racism without racists: Color blind racism and the persistence of racial inequality in the United States ( $2^{\text {nd }} \mathrm{ed}$.). Lanham, MD: Rowman\& Littlefield.

Delgado, R., \&Stefancic, J. (Eds.). (2013). Critical race theory: The cutting edge ( $3^{\text {rd }} \mathrm{ed}$.). Philadelphia, PA: Temple University Press.

Einarsdottir, H. (2012). Tragic figures of race: The dilemma of minority races in Richard Wright's and Nella Larsen's fiction. B.A. Essay, University of Iceland. Retrieved 11 February 2015 from http://skemman.is/en/item/view/1946/ 11456
McPherson, L.K., \& Shelby, T. (2004). Blackness and blood: Interpreting African American identity. Philosophy and Public Affairs, 32(2), 171-192. Retrieved 11 February 2015 from: http://www.jstor.org/stable/3557949

Pinkney, A. (2008). Red, black, and green: Black nationalism in the United States. New York: Cambridge University Press.

Radhakrishnan, R. (2006). Race and double consciousness. Retrieved 11 February 2015 from http://www.worksanddays.net/2006/Fil e04.Radha.pdf

Shelby, T. (2003). Two conceptions of black nationalism: Martin Delany on the meaning of black political solidarity. Political Theory, 31(5), 664-692. doi:10.1177/0090591703252826.

Stein, D. (2011). Barack Obama's Dreams from My Father and African American literature.European Journal of American Studies, 6(1), 1-14. doi:10.4000/ejas.9232. 